\title{
Linking metabolic dysfunction with cardiovascular diseases: Brn-3b/POU4F2 transcription factor in cardiometabolic tissues in health and disease
}

\author{
Vishwanie S. Budhram-Mahadeo ${ }^{1}$, Matthew R. Solomons ${ }^{1}$ and Eeshan A. O. Mahadeo-Heads ${ }^{1,2}$
}

\begin{abstract}
Metabolic and cardiovascular diseases are highly prevalent and chronic conditions that are closely linked by complex molecular and pathological changes. Such adverse effects often arise from changes in the expression of genes that control essential cellular functions, but the factors that drive such effects are not fully understood. Since tissue-specific transcription factors control the expression of multiple genes, which affect cell fate under different conditions, then identifying such regulators can provide valuable insight into the molecular basis of such diseases. This review explores emerging evidence that supports novel and important roles for the POU4F2/Brn-3b transcription factor (TF) in controlling cellular genes that regulate cardiometabolic function. Brn-3b is expressed in insulin-responsive metabolic tissues (e.g. skeletal muscle and adipose tissue) and is important for normal function because constitutive Brn-3b-knockout (KO) mice develop profound metabolic dysfunction (hyperglycaemia; insulin resistance). Brn-3b is highly expressed in the developing hearts, with lower levels in adult hearts. However, Brn-3b is re-expressed in adult cardiomyocytes following haemodynamic stress or injury and is necessary for adaptive cardiac responses, particularly in male hearts, because male Brn-3b KO mice develop adverse remodelling and reduced cardiac function. As a TF, Brn-3b regulates the expression of multiple target genes, including GLUT4, GSK3ß, sonic hedgehog (SHH), cyclin D1 and CDK4, which have known functions in controlling metabolic processes but also participate in cardiac responses to stress or injury. Therefore, loss of Brn-3b and the resultant alterations in the expression of such genes could potentially provide the link between metabolic dysfunctions with adverse cardiovascular responses, which is seen in Brn-3b KO mutants. Since the loss of Brn-3b is associated with obesity, type II diabetes (T2DM) and altered cardiac responses to stress, this regulator may provide a new and important link for understanding how pathological changes arise in such endemic diseases.
\end{abstract}

\section{Facts}

- Indisputable links exist between common metabolic diseases such as obesity and type II diabetes and increased risk of heart diseases.

- Molecular regulators driving these changes are not well-understood.

Correspondence: Vishwanie Budhram-Mahadeo (v.budhram-mahadeo@ucl.ac.uk) ${ }^{1}$ Molecular Biology Development and Disease, Institute of Cardiovascular Science, University College London, London, UK

${ }^{2}$ College of Medicine and Health, University of Exeter Medical School, St Luke's Campus, Exeter, UK

Edited by M. Agostini
- Emerging evidence identifies important functions for the Brn-3b/POU4F2 transcription factor in controlling homoeostasis in metabolic and cardiovascular tissues.

- Reduction/loss of Brn-3b causes metabolic dysfunction, e.g. profound hyperglycaemia and insulin resistance, as well as abnormal responses to haemodynamic stress.

\section{Open questions}

- What are the roles of Brn-3b/POU4F2 target genes in controlling normal function in insulin-responsive tissues and the heart?

\section{(c) The Author(s) 2021}

(c) (i) Open Access This article is licensed under a Creative Commons Attribution 4.0 International License, which permits use, sharing, adaptation, distribution and reproduction cc) in any medium or format, as long as you give appropriate credit to the original author(s) and the source, provide a link to the Creative Commons license, and indicate if changes were made. The images or other third party material in this article are included in the article's Creative Commons license, unless indicated otherwise in a credit line to the material. If material is not included in the article's Creative Commons license and your intended use is not permitted by statutory regulation or exceeds the permitted use, you will need to obtain permission directly from the copyright holder. To view a copy of this license, visit http://creativecommons.org/licenses/by/4.0/. 
- How does the loss of Brn and its target genes contribute to metabolic dysfunction and abnormal cardiac responses?

- Are cardiac abnormalities in male Brn-3b KO caused by direct or indirect effects in cardiac cells?

\section{Introduction}

Cardiovascular diseases (CVDs) remain the main cause of mortality globally, accounting for an estimated $31 \%$ of deaths worldwide ${ }^{1,2}$. CVDs are set to rise significantly, in line with a global obesity epidemic because metabolic diseases such as obesity and type 2 diabetes mellitus (T2DM) are known risk factors for CVDs ${ }^{3-5}$. Thus, obesity strongly correlates with increased risk of adverse cardiovascular events, including atherosclerosis, cardiac arrhythmias and heart failure ${ }^{6-8}$. Similarly, T2DM is recognised as an independent risk factor for heart disease since patients with T2DM display a higher incidence of MI with poorer outcomes compared with non-diabetic patients ${ }^{8-10}$. Despite strong evidence supporting close links between such diverse diseases, the molecular mechanisms driving such changes are still to be elucidated.

Physiological adaptation and pathological changes arise due to alterations in genes that control key cellular processes $^{11,12}$ so identifying factors that control gene expression is important for understanding the disease process. Chronic diseases such as obesity, type II diabetes and CVD, are particularly challenging because while gene expression changes may occur at early stages of the disease, the pathological changes often develop over relatively long periods. Therefore, symptoms become detectable at later stages, when irreversible tissue damage has already occurred ${ }^{9}$, thereby limiting effective treatment options and increasing the burden on population health and healthcare ${ }^{13}$. Thus, elucidating the molecular mechanisms that drive such pathological changes will improve our understanding of these diseases but also facilitate early diagnosis/treatment, aimed at minimising or reversing pathological changes before irreversible damage occurs.

Since pathological changes that drive chronic diseases are caused by altered gene expression ${ }^{11}$, then identifying the tissue-specific transcription factors that regulate such cellular genes will provide insight into the mechanisms that drive pathological changes associated with common diseases ${ }^{14-17}$. This review focuses on novel roles for the transcription factor, Brn-3b/POU4F2 (called Brn-3b) in maintaining metabolic and cardiac function.

\section{Brn-3b/POU4F2 transcription factor (TF)}

Brn-3b is a tissue-specific $\mathrm{TF}^{18-25}$ belonging to the class IV POU (Pit-1; Oct-1; Unc-86) sub-family of homeodomain TFs, and is characterised by a highly conserved POU domain that forms a helix-turn-helix (HTH) DNA binding structure ${ }^{26}$. The POU domain consists of a 60aa homeodomain, $\mathrm{POU}-_{\mathrm{HD}}$, with strong similarity to homeobox proteins and 74-82aa POU-specific domain $\left(\mathrm{POU}_{\mathrm{s}}\right)$, which is unique to POU proteins (Fig. 1A). The $\mathrm{POU}_{\mathrm{HD}}$ and $\mathrm{POU}_{\mathrm{S}}$ domains are tethered by a poorly conserved linker and act together to facilitate high-affinity

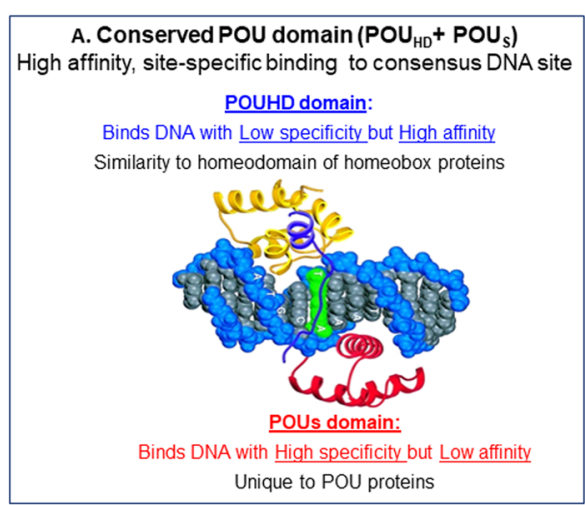

B. Genomic organisation:

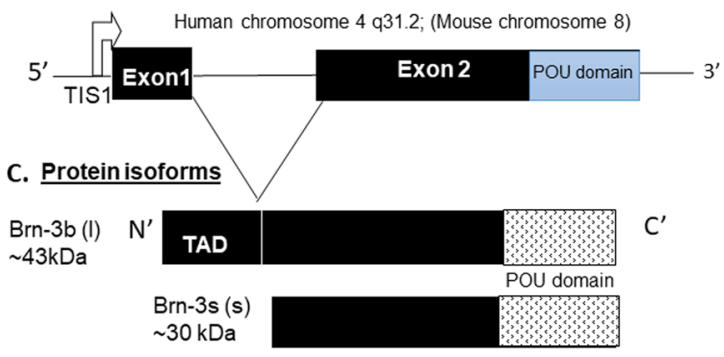

Fig. 1 Schematic figures showing the structure of the POU domain, genomic organisation of the Brn-3b gene and proteins arising from this gene. A Diagram showing a schematic model of the DNA-binding POU domain in Brn-3b TF, which is unique to the POU family of transcription factors. This domain consists of the $\mathrm{POU}_{\mathrm{HD}}$ which binds to the major groove of the DNA double helix with high affinity but low specificity while the POU-specific domain (POUs), which is unique to POU proteins, binds to DNA with high specificity but low affinity. The POUs and POU $U_{H D}$ domains are tethered together by a poorly conserved linker and together these domains confer high specificity and high-affinity DNA binding to sites in gene promoters. $\mathrm{POU}_{\mathrm{HD}} \mathrm{POU}$ homeodomain, $\mathrm{POU}_{\mathrm{S}} \mathrm{POU}$-specific domain. B Schematic diagram showing the genomic organisation of the Brn-3b locus on human chromosome 4 (mouse chromosome 8). C Schematic diagram showing Brn-3b protein isoforms, with splicing of exons 1 and 2 giving rise to the longer Brn-3b(l) while the shorter Brn-3b(s) protein is encoded by exon 2 and therefore contains the POU domain but lacks the amino-terminal transactivation domain (TAD) found in the Brn-3b (I). Approximate sizes of the proteins are indicated. TIS transcription initiation site, TAD transactivation domain, $\mathrm{N}^{\prime}=$ amino terminal, $\mathrm{C}^{\prime}$ carboxy terminal. 
site-specific binding to A/T-rich DNA sequences in the promoters of target genes, thereby regulating the rate of gene transcription ${ }^{27,28}$.

Brn-3b was originally isolated from proliferating neuronal derived cell line ND7, due to its high homology to the POU domain of the related Brn-3a protein ${ }^{29}$. However, these proteins are encoded by distinct genes on different chromosome, i.e. Brn-3b: human chr 4q31.2 (mouse chr 8) and Brn-3a: human chr 13q31.1 (mouse chr 14) ${ }^{30,31}$. The Brn-3b gene consists of two exons separated by a single intron (Fig. 1B) and can give rise to two distinct protein isoforms, i.e. Brn-3b(s), encoded by exon 2 only and the longer $\mathrm{Brn}-3 \mathrm{~b}(\mathrm{l})$ isoform, produced by splicing of exons 1 and 2. Consequently, Brn-3b(l) contains an N' transactivation domain encoded by exon 1, not found in Brn-3b (s) (Fig. 1C). However, both isoforms contain the DNAbinding POU domain, encoded by exon 2, so can bind to the BRNF DNA consensus site to regulate (activate or repress) tissue-specific target genes ${ }^{30,31}$. In addition, a feedback mechanism facilitates auto-regulation by these isoforms to control protein levels ${ }^{32-34}$. At the amino acid level, Brn-3b is highly conserved across diverse species (Table 1), suggesting important functions in determining cell fate/function ${ }^{28}$.

Since Brn-3b was isolated from neuronal cells, early studies were focused on its expression in the central nervous system (CNS), e.g. midbrain, hindbrain and retinal ganglion cells (RGC) $)^{25,35,36}$ and peripheral nervous system (PNS), e.g. afferents of dorsal root ganglia (DRG); cranial nerves $\mathrm{V}$, VIII, IX, X and $\mathrm{VII}^{37}$. However, subsequent studies have shown Brn-3b expression in other diverse tissues including reproductive tract tissue (testis, ovary and breast epithelium $)^{22,33,34,38-44}$, peripheral blood mononuclear cells (PBMC) ${ }^{23,45,46}$, metabolic tissue (adipocytes, skeletal muscle and liver $)^{20}$, cardiovascular tissues e.g. cardiomyocytes $^{18,19,21,39,47}$ and vascular smooth muscle cells (VSMC) (Fig. 2). Moreover, early studies using constitutive Brn-3b knockout (KO) mice revealed essential roles for Brn-3b in maintaining survival and specification of retinal ganglion cells (RGCs), since homozygous Brn-3b KO mutants are blind, due to loss of $\sim 70 \%$ of RGCs, postnatally ${ }^{2,25,30,35}$. More recent studies using these mutants have also highlighted essential and previously unknown roles for Brn-3b in regulating genes that control the fate and function of metabolic, vascular and cardiac cells ${ }^{18,20}$ (see later).

\section{Brn-3b controls gene transcription directly or indirectly by interaction with other regulators}

As a transcription factor Brn-3b can drive complex cellular effects, including proliferation ${ }^{42,43,48}$, differentiation, survival $^{49,50}$ and metabolic processes ${ }^{20}$ by controlling the

\section{Table 1 Comparison of Brn-3b amino acid homology between human and rodents (mouse and rat) and zebrafish.}

\begin{tabular}{ll}
\hline Species & $\begin{array}{l}\text { \% Homology to } \\
\text { human Brn-3b }\end{array}$ \\
\hline Mouse & $97.3 \%$ \\
Rat & $97.3 \%$ \\
Zebrafish & $87 \%$ \\
\hline
\end{tabular}

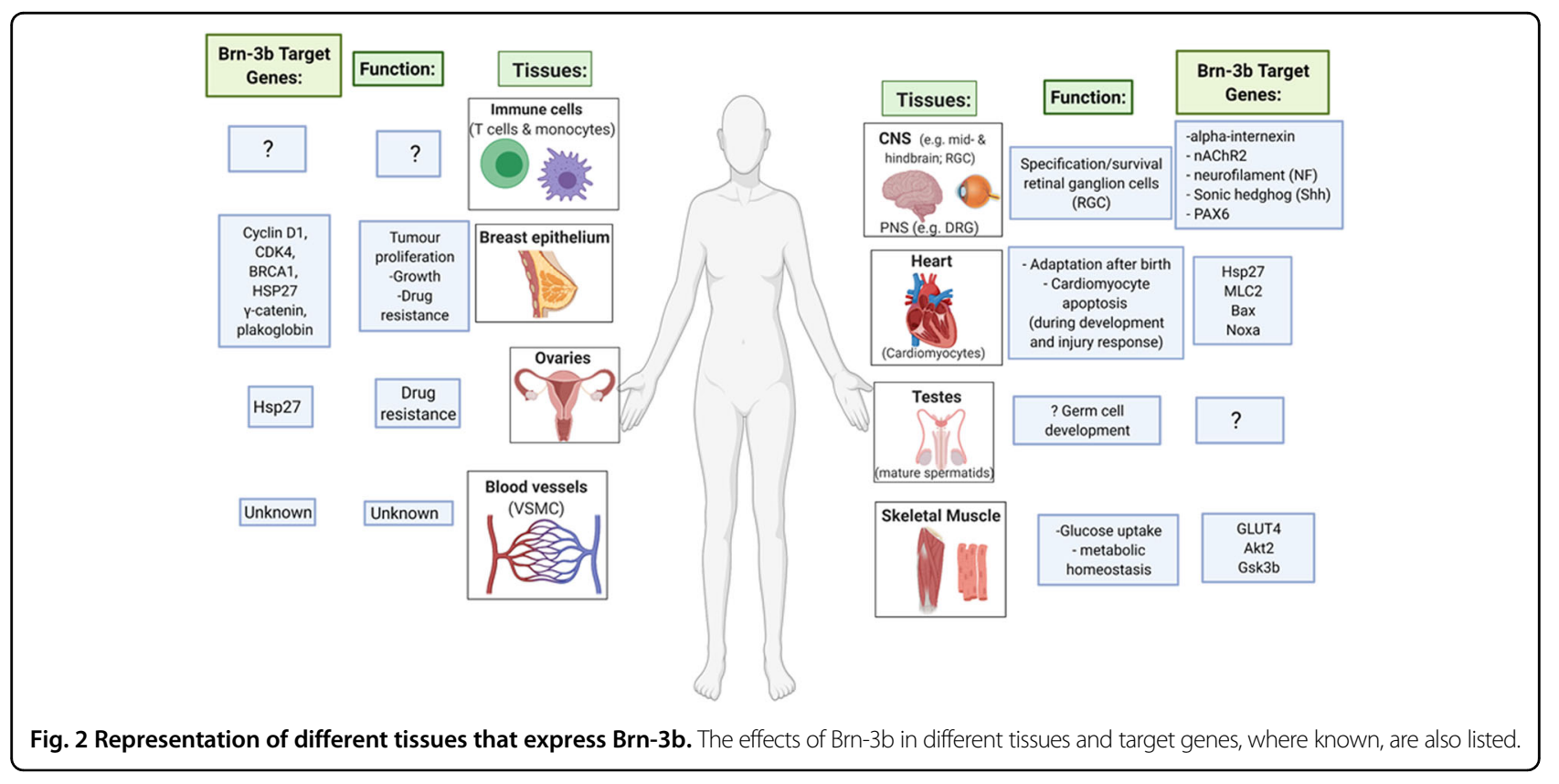


Table 2 List of known Brn-3b target genes with selected cellular functions and potential effects of changes on clinical conditions.

\begin{tabular}{|c|c|c|}
\hline Target genes & Selected cellular function & Effects of altered gene expression \\
\hline \multicolumn{3}{|c|}{ Genes directly activated by Brn-3b } \\
\hline $\begin{array}{l}\text { Cyclin D1 } \\
\text { and CDK4 }\end{array}$ & $\begin{array}{l}\text { Cell cycle progression/proliferation, inhibit gluconeogenesis in } \\
\text { metabolic tissues; increased expression in stressed heart }\end{array}$ & $\begin{array}{l}\text { Increase associated with cancer; loss or reductions linked to } \\
\text { abnormal cardiac responses to stress, T2DM }\end{array}$ \\
\hline GLUT 4 & Glucose uptake/metabolism; insulin responsiveness & $\begin{array}{l}\text { Reduced expression linked to insulin resistance in T2DM Loss } \\
\text { or reduction in stressed hearts }\end{array}$ \\
\hline HSP-27 & Cell survival, actin polymerisation, cell motility & $\begin{array}{l}\text { Drug resistance/migration in cancers Cardioprotective in } \\
\text { stressed hearts }\end{array}$ \\
\hline $\mathrm{SHH}$ & Morphogen with pleotropic effects & $\begin{array}{l}\text { RGC development; heart development, coronary } \\
\text { revascularisation }\end{array}$ \\
\hline $\mathrm{nACHr} 2$ & Neurotransmitter; activation of neuromuscular junction & \\
\hline \multicolumn{3}{|c|}{ Genes repressed by Brn-3b } \\
\hline a-internexin & Intermediate filament & \\
\hline BRCA1 & Cell cycle inhibitor, apoptosis & Reduced expression or loss of function in cancers \\
\hline Plakoglobin & Adhesion molecule, adherence junction, & Reduced expression in cancers \\
\hline GSK3 $\beta$ & $\begin{array}{l}\text { Pleotropic protein kinase, controls glycogen synthesis and glucose } \\
\text { metabolism; negative regulator of hypertrophy }\end{array}$ & Increased expression in T2DM, heart disease \\
\hline \multicolumn{3}{|c|}{ Genes indirectly regulated by Brn-3b (upon interaction with other regulators) } \\
\hline $\begin{array}{l}\text { Bax; Noxa; Puma } \\
(\text { Brn-3b + p53) }\end{array}$ & Apoptosis & Heart failure \\
\hline $\begin{array}{l}\text { Hsp27 (Brn-3b + } \\
\text { ER) }\end{array}$ & Survival, growth and cell motility & $\begin{array}{l}\text { Drug resistance; migration in cancer cells Cardioprotective in } \\
\text { stressed hearts }\end{array}$ \\
\hline
\end{tabular}

expression of tissue- or signal-specific target genes, depending on cell types and growth conditions (see Table 2).

Direct effects can arise from Brn-3b binding to BRNFbinding sites, on target gene promoters or enhancers and either activating or repressing transcription of target genes (Table 1 and Fig. 3A). For example, in neuronal cells, Brn-3b activates the nicotinic acetylcholine receptor 2 (nAChR2) subunit promoter ${ }^{51}$ but represses $\alpha$-internexin $^{52}$ and neurofilament ${ }^{53}$. However, in RGCs, Brn-3b activates other genes including PAX6, sonic hedgehog (SHH) but represses DLX1/2 $2^{54-56}$. In proliferating cells (e.g. breast cancers), Brn-3b can increase cell division ${ }^{43,48}$ by activating promoters of genes encoding cell cycle proteins cyclin $\mathrm{D} 1^{40}$ and $\mathrm{CDK} 4^{42}$, while repressing the tumour suppressor BRCA $1^{44}$. Brn-3b also confers drug resistance and migratory potential in cancer cells by indirectly activating heat shock protein 27 (Hsp27) ${ }^{34,39}$, while repressing adhesion molecule, plakoglobin (gamma catenin $)^{41}$. As such, elevated Brn-3b is associated with growth, drug resistance and migratory potential in different cancers ${ }^{34,43,44,48,57}$; Brn-3b is also implicated in the regulation of metabolic genes that control glucose uptake, e.g. GLUT4 and GSK3 $\beta^{20}$ (later).
However, Brn-3b can control gene expression indirectly by interacting with other cellular proteins to regulate other target genes. For instance, in RGCs, Brn-3b interacts with Isl- 1 and DLX $1 / 2$ to control RGC gene expression during retinal development $t^{50,58,59}$. Other notable Brn-3b interacting partners, oestrogen receptor (ER ${ }^{60}$ and p53 tumour suppressor protein ${ }^{61}$ are discussed below to highlight the complex mechanisms by which Brn-3b controls cellspecific or condition-specific effects (Fig. 3B).

\section{Brn-3b interaction with ERa}

Brn-3b interaction with $\mathrm{ER} \alpha$ was originally identified and characterised in epithelial-derived breast cancer cells, which express both proteins ${ }^{60,62}$. In these cells, Brn-3b interacts and cooperates with ER $\alpha$ to maximally transactivate ERE containing promoters e.g. Hsp27 (Fig. 3) ${ }^{34,60}$. As a target gene, Hsp27 is particularly important because of its diverse effects on cell function, including inhibition of apoptosis and regulation of cytoskeletal dynamics, e.g., actin polymerisation $^{63-65}$. Consequently, maximal activation of Hsp27 by co-expression of Brn-3b and ER may promote cell survival, drug resistance and metastatic potential in cancer cells ${ }^{66-69}$. 
B. Indirect target genes

A. Direct target genes

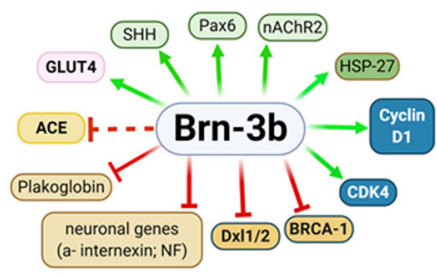

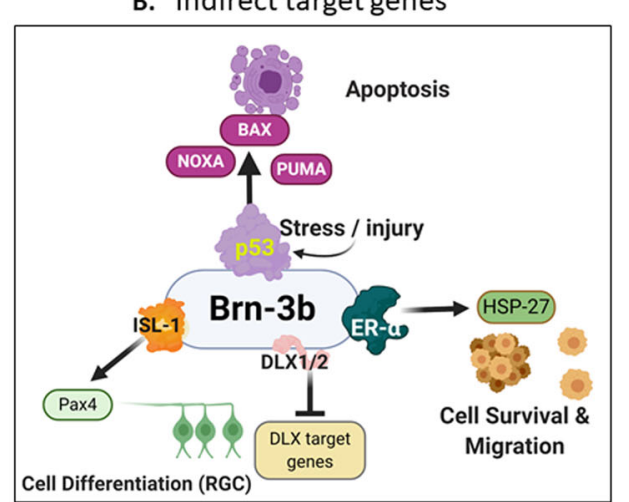

Fig. 3 Schematic diagram showing the effects of Brn-3b on known target genes. A Representation of known target genes that are directly regulated by Brn-3b. Green arrows indicate genes that are directly activated activated by Brn-3b and red bars represent genes that are repressed. B Shows genes that are indirectly regulated by Brn-3b, upon interaction with other cellular proteins, including the oestrogen receptor alpha (ER-a), p53 tumour suppressor gene; ISL1 and DLX proteins, as indicated. The effects on cell fate are also indicated.

However, like Brn-3b, Hsp27 is required for normal heart development and is also implicated in cardioprotection in stressed adult hearts ${ }^{70-73}$. Since ER proteins are also expressed in the heart, vasculature and metabolic tissues $^{74-79}$, it is likely that co-expression of Brn-3b and ER in these tissues may also regulate relevant target genes. Therefore, it is important to analyse if/how co-expression of Brn-3b and ER may also affect gene expression and cell fate in cardiometabolic tissues.

\section{Brn-3b interaction with p53 controls apoptosis}

Brn-3b also interacts with $\mathrm{p} 53$ protein ${ }^{61}$ and when coexpressed, Brn-3b cooperates with p53 to increase the transcription of pro-apoptotic target genes e.g. $\mathrm{Bax}$ and Noxa, thereby promoting cell death through the mitochondrial pathway (Fig. 3B and Table 1) ${ }^{47,61}$. In fact, the Brn-3b:p53 interaction may be necessary for maximal induction of apoptotic genes, since primary neuronal cells prepared from Brn-3b KO mutants express reduced pro-apoptotic $B a x$ and are resistant to apoptosis-inducing staurosporine, despite p53 expression being unchanged ${ }^{61}$.

The cooperation between Brn-3b and p53 to enhance apoptosis has been pivotal for elucidating how cell fate decisions are determined under different conditions. For example, while Brn-3b can promote cell proliferation and growth by activating cell cycle genes such as CDK4 and cyclin D $1^{40,80}$, induction of $\mathrm{p} 53$ in Brn-3b expressing cells (e.g. by stress or injury) can cause conflicting signals and trigger a mitotic crisis ${ }^{61,81}$. This is because p53 can inhibit cell growth by inducing cell cycle inhibitors e.g. $\mathrm{p} 21^{\text {cip } 1 / \text { waf } 182,83}$ or promote apoptosis by activating apoptotic genes such as Bax, Noxa and Puma ${ }^{84,85}$. Under such conditions, cooperation between Brn-3b and p53 to synergistically activate pro-apoptotic genes and trigger apoptosis. provides a paradigm to explain how cell fate is determined in the face of conflicting signals ${ }^{86}$ and also highlights the complex mechanisms by which Brn-3b drives diverse effects on cell fate (Fig. 3). This interaction between Brn-3b and p53 is also important in controlling the gene expression and fate of cardiomyocytes, in both developing and adult hearts ${ }^{18,57}$. The mechanisms associated with controlling effects in cardiomyocytes will be discussed in more detail later, but it is noteworthy that ectopic increases in Brn-3b in the developing heart can induce apoptosis if co-expressed with p53 and thereby contribute to congenital heart defects ${ }^{19}$. Similarly, Brn$3 \mathrm{~b}$ is increased in cardiomyocytes of stressed or injured adult hearts and is required for the maximal induction of pro-apoptotic genes by p53 in the infarct zone following coronary artery ligation $^{18}$ (described below). Therefore, the effects of Brn-3b on gene expression and cell fate must be considered in the context of cell type as well as growth conditions that induce other co-regulators.

\section{Brn-3b in metabolic and cardiovascular tissues}

The remainder of this review will focus on Brn-3b in metabolic and cardiovascular tissues, where it has a novel and potentially important roles in controlling gene expression and cell fate.

\section{Brn-3b in metabolic tissues}

Recent studies have shown that Brn-3b is expressed in insulin-responsive metabolic tissues, including skeletal muscle, liver and adipose tissues ${ }^{20}$ and in vitro studies using myoblast- derived $\mathrm{C} 2 \mathrm{C} 12$ cells have confirmed that Brn-3b is, itself, regulated by key metabolites and pathways that control metabolic processes since Brn-3b mRNA and protein are increased by glucose but inhibited by insulin ${ }^{20}$. Furthermore, compelling evidence from 
Brn-3b KO mice supports essential roles for Brn-3b in controlling important metabolic processes since $\mathrm{KO}$ mutants develop increased body weight when compared to WT, despite no significant differences in food intake. Glucose-tolerance studies have shown that these mutants develop profound hyperglycaemia and insulin resistance characteristic of T2DM following glucose bolus administration ${ }^{20}$. Importantly, Brn-3b is also significantly reduced in tissues taken from normal mice fed on high-fat diet to induce obesity, and such reduction correlates with the development of hyperglycaemia and insulin resistance. Since the loss of Brn-3b (KO mutants) or reduced expression (obese mice) is linked to marked metabolic dysfunction, these data indicate important roles for Brn$3 \mathrm{~b}$ in controlling metabolic processes ${ }^{20}$.

Potential metabolic target genes regulated by Brn-3b in skeletal muscle have been identified using mRNA from Brn$3 \mathrm{~b} \mathrm{KO}$ tissues and matched WT controls that was used to screen a disease-focused $\mathrm{RT}^{2}$ Profiler PCR Array (containing 84 metabolic genes), followed by qRT-PCR to confirm changes. Noteworthy target genes that are reduced upon loss of Brn-3b include the insulin-dependent glucose transporter, GLUT4 and angiotensin 1-converting enzyme (ACE1), while the glycogen-synthase kinase 3-beta, (GSK3 3 ) was significantly increased in tissues from Brn-3b $\mathrm{KO}$ mice ${ }^{20}$. Based on the known functions of these genes, it is likely that such changes will contribute to the abnormal metabolic phenotype seen in Brn-3b KO mutants. For example, GLUT4 plays a central role in insulin-mediated glucose uptake in diverse tissues ${ }^{87}$ and reduction of this transporter e.g. in GLUT4 ${ }^{+/-}$mice is associated with peripheral insulin resistance, similar to that seen in Brn-3b KO mutants ${ }^{88}$. Co-transfection studies and ChIP assays confirm that Brn-3b can directly activate the GLUT4 gene promoter while significant reduction of GLUT4 mRNA and protein levels in skeletal muscle and adipose tissues taken from Brn-3b KO mice ${ }^{20}$ confirm that Brn-3b is important for regulating GLUT4 expression. Therefore, Brn-3b regulation of such target genes will be controlling normal metabolic processes in insulin-responsive tissues.

In contrast, increased expression of GSK3 $\beta$ in Brn-3b $\mathrm{KO}$ tissues suggests that Brn-3b may normally repress this enzyme and therefore loss of Brn-3b will cause corresponding increases in GSK3 $\beta$. In metabolic tissues, GSK3 $\beta$ controls glycogen synthesis by phosphorylating and inactivating glycogen synthase ${ }^{89}$, and is also implicated in controlling glucose metabolism by its effects on other metabolic enzymes such as glucose-6-phosphate and its receptors e.g. insulin receptor, IRS1 ${ }^{90,91}$. Accordingly, increased GSK3 $\beta$ in metabolic tissues is implicated in diseases such as T2DM and elevated expression has been reported in skeletal muscle taken from diabetic patients with insulin resistance ${ }^{89-91}$. Therefore, increased GSK3 $\beta$ upon loss of Brn-3b may also contribute to metabolic dysfunction in Brn-3b KO mutants.

Other known Brn-3b target genes such as cyclin D1 and CDK4 are also implicated in controlling glucose metabolism, independently of cell cycle regulation. In this context, activation of cyclinD1-CDK4 can cause inhibition of gluconeogenesis by regulating the activity of GCN5 histone acetyltransferase and thereby inhibiting $\mathrm{PGC} 1 \alpha$, a regulator of mitochondrial biogenesis ${ }^{92}$. Although not present on the PCR array used for screening, reduced cyclin D1 and CDK4 upon loss of Brn-3b could also contribute to metabolic dysfunction in Brn-3b KO mutants.

\section{Brn-3b in the developing heart}

Brn-3b is expressed in cardiomyocytes of the developing heart ${ }^{19,21}$ and although found at low levels in adult hearts under normal conditions, it is strongly re-expressed following stress and injury ${ }^{18,47}$. This is similar to other foetal cardiac TFs such as NKX2.5, HAND2 and Brn-3a, which are re-expressed in adult hearts following stress/injury and are important for driving cellular responses to injury $^{47,93,94}$. Therefore, studying the roles of such regulators during the development of the mature fourchambered heart ${ }^{95,96}$ can provide insight into potential mechanisms of action in stressed adult hearts ${ }^{97}$.

In the developing heart, Brn-3b has essential but partially redundant roles with the related Brn-3a TF, with which it shares $>95 \%$ homology in the POU domain ${ }^{57}$ so can drive compensatory transcriptional effects on some target genes e.g. activation of $\mathrm{Hsp}_{2} 7^{21}$. However, differences outside the POU domain may also cause antagonistic effects on other target genes and elicit opposing effects on cell fate ${ }^{47,52}$. For example, while Brn-3b cooperates with p53 to maximally activate apoptotic genes and increase cell death, Brn-3a blocks p53 activation of pro-apoptotic genes but co-operates with p53 to increase the cell cycle inhibitor, p21 cip1/Waf1, thereby promoting survival and differentiation ${ }^{47,61,98,99}$.

Importantly, Brn-3b is significantly increased in hearts from Brn-3a KO mutants and can partially compensate for the loss of Brn-3a, because double KO (Brn-3a $\mathrm{a}^{-1-}$ : Brn- $3 \mathrm{~b}^{-1-}$ ) mutants are embryonic lethal and die by E8.5 (i.e. before cardiac looping $)^{19,100}$. However, it was possible to use zebrafish (ZF) embryos as a model for studying Brn-3a and Brn-3b during early heart development because both proteins are highly conserved $(>80 \%)$ between ZF and mammals (Table 1) and are expressed in ZF heart by $48 \mathrm{~h}$ post fertilisation (HPF) ${ }^{19}$. Studies using ZF embryos have provided evidence for essential roles for Brn-3a and Brn-3b in controlling normal heart development since reducing both proteins, using morpholinos, is sufficient to block cardiac looping ${ }^{19}$, an essential stage in heart morphogenesis ${ }^{95,101}$.

Although increased Brn-3b may partially compensate for Brn-3a loss in the developing heart, ectopic increases 
in Brn-3b and resultant increases in its target genes e.g. cyclin D1 correlate with hyperproliferation in heart valves, ventricular wall and septum in E14.5 Brn-3a KO mutant hearts $^{21}$. At later stages, induction of p53, when combined with such increased Brn-3b results in cooperative activation of pro-apoptotic genes, Bax, Noxa; Puma and increased cell death. Therefore, by E18.5, Brn-3a KO hearts display cardiomyocyte death, reduced myocardial compaction, hyper-trabeculation and myocardial fissures, which may contribute to the death of mutants shortly after birth $^{19,102,103}$.

The molecular mechanisms underlying the compensatory effects between Brn-3b and Brn-3a in the heart are still being investigated, but are likely to result from regulation of common target genes e.g. HSP27, which contributes to cardiomyocyte differentiation and adaptation to stress in either the developing heart or in stressed adult hearts ${ }^{21,72,104,105}$. Moreover, this study also shows how the complex interplay between Brn-3b and other regulators can control cardiomyocyte fate during normal heart development and may also be pertinent to stress responses in adult hearts.

\section{Brn-3b in adult hearts following acute injury or chronic stress}

As previously mentioned, Brn-3b is found at relatively low levels in normal adult hearts but is significantly upregulated in cardiomyocytes following myocardial infarction (MI) or haemodynamic stress e.g. pressure/volume overload ${ }^{19,47}$.

In the context of acute injury, Brn-3b mRNA is rapidly induced in adult rat hearts, following coronary artery ligation. This model, which induces ischaemia/hypoxia and is commonly used to mimic MI, causes rapid increases in Brn$3 \mathrm{~b}$ mRNA by $1 \mathrm{~h}$ post injury that continues to increase, with maximal expression at $24 \mathrm{~h}$. Levels remain above baseline at 1 -week post ligation ${ }^{47}$. Detailed localisation studies in heart sections have confirmed that Brn-3b is increased throughout the injured heart, with expression being detected in cardiomyocytes around the infarct zone as well as in the remote, uninjured myocardium.

Cellular processes in the myocardium can vary significantly depending on the location in relation to the site of injury. Therefore, Brn-3b expression throughout the injured heart reflects potentially complex effects for this TF in regulating cellular responses at different locations in the injured myocardium. This is highlighted by analysis of Brn-3b co-localisation with p53, in the reported study ${ }^{47}$ showing that while Brn-3b is expressed throughout the heart, p53 is only detected in cardiomyocytes around the infarct zone. Importantly, co-localisation of p53 with Brn$3 \mathrm{~b}$ in injured cells correlates with the induction of proapoptotic genes (e.g. Bax, Noxa, Puma) and associated enhanced apoptosis ${ }^{19,47}$. Indeed, studies carried out using primary rat ventricular cardiomyocyte cultures (NRVC) indicate that Brn-3b cooperation with p53 is required for the maximal induction of pro-apoptotic genes such as $\mathrm{Bax}$ and Noxa, following ischaemic or hypoxic injury. Thus, short interfering RNA (siRNA) to reduce endogenous Brn-3b expression in NRVM cultures is sufficient to attenuate Bax and Noxa expression following ischaemia/ reoxygenation injury, despite p53 expression remaining unchanged $^{47}$. Therefore, co-expression of Brn-3b with p53 may be required for maximal induction of proapoptotic genes and effective clearance of non-viable cardiomyocytes in the infarct zone.

While the reported effects have focused on the cooperation between Brn-3b and p53 in activating proapoptotic gene expression and cell fate in injured cardiomyocytes within the infarct zone, the effects of increased Brn-3b in the remote, uninjured myocardium (which lacks p53 and shows no evidence of apoptosis), remains to be elucidated ${ }^{47}$. Under such conditions, cardiomyocytes in the remote, uninjured myocardium also undergo extensive hypertrophic adaptation to compensate for the increased workload caused by the loss of contractile myocardium. However, the factors that control genes required for such adaptive responses in the remote myocardium are still not fully understood ${ }^{106}$. It is therefore intriguing that recent evidence has highlighted essential roles for Brn-3b in controlling adaptive responses in hypertrophic hearts (see below) ${ }^{18}$. Although speculative, it is possible that Brn-3b may control adaptive responses in remote myocardium and thereby help to maintain cardiac output and function of the injured heart.

\section{Brn-3b in adaptive hypertrophic responses following chronic haemodynamic stress}

More recently, Brn-3b has been implicated in previously unknown roles for controlling adaptive hypertrophic responses in adult hearts, following sustained haemodynamic stress that increases cardiac workload ${ }^{18}$. Cardiac hypertrophy occurs in response to increased workload on the heart because terminally differentiated cardiomyocytes have limited proliferative capacity, and therefore undergo hypertrophy to maintain cardiac output ${ }^{107}$. Such responses are characterised by extensive genetic reprogramming, cytoskeletal reorganisation and metabolic adaptation depending on the type and duration of stress $^{108}$. For example, increased physiological demands (pregnancy or endurance exercise) cause reversible hypertrophic responses ${ }^{109}$ while chronic haemodynamic stresses (pressure or volume overload), can trigger a complex, biphasic response in which early adaptive responses are necessary for maintaining cardiac output/ function ${ }^{110}$, while sustained stresses trigger maladaptive changes, including cardiomyocyte apoptosis and interstitial fibrosis and remodelling; which underpins the pathogenesis of heart failure ${ }^{111,112}$. These distinct 
responses are driven by gene expression changes and are associated with different cellular responses. For instance, adaptive hypertrophic responses are associated with reexpression of foetal genes, including natriuretic peptides, (ANP/BNP), which help to normalise wall stress by modulating myocyte growth and fibroblast proliferation ${ }^{113,114}$; $\beta$-MHC, which is linked to sarcomeric reorganisation and increased metabolic genes e.g. GLUT4 to facilitate metabolic switching ${ }^{115-121}$. In contrast, pathological changes are associated with increased expression of pro-apoptotic genes (e.g. p53 and Bax) that drives cardiomyocyte apoptosis and pro-fibrotic regulators e.g. TGF- $\beta$ signalling pathways, linked to fibrosis and remodelling ${ }^{110}$. However, the molecular mechanisms that control the transition from adaptive to maladaptive responses are not fully understood. Therefore, identifying transcription factors that control genes required for adaptive hypertrophic responses in the heart will be important for controlling functional outcomes in stressed hearts $^{107}$.

In this regard, Brn-3b is a potential contender since in-vivo and in-vitro studies show that this TF is strongly activated by known hypertrophic stimuli, including angiotensin II (AngII), endothelin and calcineurin A (CnA), either in intact hearts or in isolated primary cardiomyocyte cultures ${ }^{18}$. Detailed analysis of the Brn-3b promoter also shows that activation by AngII occurs via MAPK/ERK1 signalling while $\mathrm{CnA}$ acts via NFAT activation and the convergence of such distinct signalling pathways in activating the Brn-3b promoter suggests that this regulator plays a central role in controlling hypertrophic responses in the heart ${ }^{18,107}$.

The roles of Brn-3b as a key regulator of cardiac hypertrophy are also supported by the fact that Brn-3b and its target genes, GLUT4 and cyclinD1 are increased in hypertrophic cardiomyocytes expressing $\beta$-MHC and showing characteristic sarcomeric reorganisation ${ }^{18}$. Furthermore, studies carried out using Brn-3b KO mice, showed that loss of Brn-3b causes attenuated hypertrophic responses to AngII treatment, as confirmed using multiple endpoints, including heart weight:body weight (HW:BW) ratio, LV mass, cardiomyocyte cell volume and lack of hypertrophic marker, $\beta$-MHC, when compared with controls ${ }^{18}$. Importantly, loss of Brn-3b also affects heart function in male mice, as assessed using echocardiography and pressure-volume loop analysis. Thus, hearts from male Brn-3b KO mice display adverse functional changes, including reduced cardiac output (CO) and ejection fraction (EF), but increased end-systolic volume (ESV). This correlates with histological changes such as increased extracellular matrix (ECM) deposition, extensive fibrosis and pathological remodelling in the LV wall and around the coronary artery when compared with appropriate controls $^{18}$. At the molecular level, Brn-3b target genes e.g. GLUT4 are significantly reduced male in Brn-3b KO hearts and may contribute to the maladaptive cardiac responses following AngII treatment. These data suggest that Brn-3b is necessary for the male heart to undergo adaptive hypertrophic changes following haemodynamic stress and loss of Brn-3b may contribute to maladaptive remodelling associated with progression to heart failure.

\section{Brn-3b: linking metabolic dysfunction and CVD}

The predicted global increase in heart disease is strongly influenced by the current surge in metabolic diseases, such as obesity and $\mathrm{T}_{2} \mathrm{DM}^{1,122-124}$. Therefore, elucidating the molecular mechanisms that link such diverse systemic changes in cardiovascular and metabolic systems will be useful for understanding the disease processes but can also enable earlier intervention to prevent or reverse adverse changes before the onset of irreversible pathology that underlies heart diseases ${ }^{125}$.

Data emerging from recent studies have shown that reduction or loss of Brn-3b and its target genes are linked to metabolic dysfunctions as well as maladaptive cardiac responses and may therefore help to understand the molecular basis linking metabolic diseases and CVDs ${ }^{18,33}$. Many observations that link the loss of Brn-3b with metabolic dysfunction and adverse cardiac responses to stress arise from studies using the global Brn-3b KO mice . However, these are strongly supported by additional data using either wild-type mice or in-vitro models ${ }^{18-20,47}$. For example, while the first evidence showing an association between a loss of Brn-3b and metabolic dysfunction (hyperglycaemia and insulin resistance) has been identified using constitutive Brn-3b KO mutants in vitro studies have confirmed that Brn-3b, is itself, regulated by key metabolites such as glucose, insulin and fatty acids, which are dysregulated in obesity and $\mathrm{T} 2 \mathrm{D}^{20}$. Moreover, in-vivo studies carried out using wild-type mice show that dietinduced obesity, which causes hypoglycaemia insulin resistance also correlated with significant reduction of Brn-3b in metabolic tissues ${ }^{20}$.

Similarly, in-vivo models have been pivotal for demonstrating that $\mathrm{Brn}-3 \mathrm{~b}$ is induced in stressed adult hearts e.g. following AngII infusion or coronary artery ligation in WT mouse and rat models and is supported by using in vitro cultures of isolated primary cardiomyocytes to confirm Brn-3b induction, primarily in cardiomyocytes. However, the requirement for Brn-3b in controlling adaptive responses is convincingly demonstrated from studies in the constitutive Brn-3b KO mutants, which display attenuated hypertrophic responses to AngII treatment, when compared with responses in WT controls. The adverse cardiac responses in male Brn-3b KO hearts have also provided invaluable evidence to support the essential roles for Brn-3b in driving adaptive responses to stress.

As a TF, Brn-3b can mediate diverse effects by controlling the expression of different target genes in a tissueor condition-specific manner. Identification of GLUT4 
and GSK3 3 as potential Brn-3b target genes in metabolic tissues such as skeletal muscle and adipose tissue suggests important roles for this regulator in controlling metabolic processes. However, these genes are also expressed in the heart, so it is important to consider how changes in expression may affect such diverse tissues. For instance, in metabolic tissues, GLUT4 potentiates insulin-mediated glucose uptake and reduced GLUT4 levels correlate with hyperglycaemia and insulin resistance in insulinresponsive tissues, as seen in Brn-3b KO mice. However, this glucose transporter is also relevant in the stressed heart when metabolic switching (i.e. fatty acid oxidation to glucose utilisation) occurs as part of the adaptive hypertrophic response. Accordingly, reduced GLUT4 expression in Brn-3b KO hearts may contribute to the adverse responses to stress ${ }^{121,126}$.

Similarly, GSK3 $\beta$ is a key regulator of glucose homoeostasis and increased expression in metabolic tissues is strongly associated with insulin resistance. Therefore, increased GSK3 $\beta$ expression in Brn-3b KO tissues suggest that Brn-3b may normally repress GSK3 $\beta$ and loss of Brn$3 \mathrm{~b}$ will result in increased expression in mutant tissue, thereby contributing to metabolic dysfunction ${ }^{20}$. However, GSK3 $\beta$ is also a negative regulator of cardiac hypertrophy in adult hearts ${ }^{89,90,127}$ and increased expression in the heart is associated with attenuated hypertrophic responses ${ }^{128,129}$, also observed in Brn-3b KO mutant hearts following AngII treatment. GSK3 $\beta$ is also activated in the heart during ischaemic injury and has been implicated in adverse post-MI remodelling since GSK3 $\beta$ KOs show preserved LV function following injury ${ }^{130}$. It will be important to elucidate the mechanism by which this TF controls GSK3 $\beta$ expression in cardiomyocytes to understand how Brn-3b contributes to adaptive responses and why the loss of Brn-3b causes maladaptive responses in stressed adult hearts.

It is also important to note that the initial screening for Brn-3b target genes in metabolic tissues was done using a highly targeted approach of screening PCR arrays with 84 selected metabolic genes. However, this array did not include many known Brn-3b target genes including sonic hedgehog (shh), cyclin D1 and CDK4, which are implicated in controlling metabolic processes and/or cardiac responses, under different conditions ${ }^{92}$. For example, the pleiotropic morphogen $\mathrm{SHH}$ was identified as a potential Brn-3b target gene in $\mathrm{RGC}^{54,131}$, but is also essential for normal heart development ${ }^{132}$ and cardiac responses to injury. Thus, SHH activation in the heart, following ischaemia-reperfusion injury, confers cardioprotective effects on the coronary vasculature and cardiomyocyte contractility $^{133}$ and its inhibition is associated with increased infarct size and poor cardiac function following $\mathrm{MI}^{134}$ and poor cardiac function in diabetic mouse hearts ${ }^{135}$. Therefore, it is important to determine if Brn-3b regulates $\mathrm{SHH}$ expression in the injured heart because then loss of Brn-3b and reduced $\mathrm{SHH}$ may contribute to abnormal cardiac responses following stress/injury in Brn3b KO hearts. Similarly, Brn-3b target genes, cyclinD1 and CDK4, which normally control cell cycle progression, are also implicated in controlling gluconeogenesis by blocking PGC1 $\alpha^{92}$. CyclinD1 is also increased in adult hearts following chronic stress or injury but its role in hypertrophic responses is not fully understood ${ }^{18}$. Therefore, the reduction of such Brn-3b target genes may also contribute to the adverse effects seen in Brn-3b KO hearts.

The co-existence of metabolic and cardiovascular dysfunctions in the constitutive Brn-3b $\mathrm{KO}$ mutants combined with these findings support Brn-3b TF as an important regulator of metabolic processes and adaptive cardiac responses to stress, especially in male hearts (Fig. 4). While this study has focused on how the loss of Brn-3b affects male hearts, it will also be important to study the cardiac responses of female $\mathrm{KO}$ hearts to stress. This is important because Brn-3b and ER can cooperate to regulate key target genes while oestrogens and ERs have known beneficial cardiac effects, particularly in premenopausal women ${ }^{136,137}$. At present, the co-expression and effects of Brn-3b and ER in the heart remain to be investigated and may help to understand the molecular basis for male-female differences in manifestation and outcome of heart disease ${ }^{136,137}$.

It is also noteworthy that both cardiac and metabolic diseases are strongly associated with pro-inflammatory responses ${ }^{5,14}$, mediated by immune cells and Brn-3b is highly expressed in monocytes and $\mathrm{T}$ lymphocytes that are implicated in such effects ${ }^{45,46}$. Although potential roles for Brn-3b in controlling inflammatory responses are still being investigated, this raises important questions about the inflammatory milieu generated by the loss of Brn-3b and could form part of an interesting interface through which inflammatory responses may drive pathological changes in diverse cell types, and thereby impact on the development of metabolic dysfunction and cardiovascular diseases (Fig. 5).

\section{Perspective}

This review explores Brn-3b/POU4F2 as a novel regulator of metabolic function and cardiac responses in male hearts, which is based on data from different experimental models and provides compelling evidence to support key roles for this regulator in controlling both metabolic and cardiac responses to stress. While cardiac-specific Brn-3b target genes are still to be identified, the coexistence of metabolic dysfunction and cardiac abnormalities in Brn-3b $\mathrm{KO}$ mutants, along with functions of its known target genes in such processes have provided a working model by which loss of this regulator could contribute to cardiometabolic dysfunction and disease (Fig. 5). Since global 


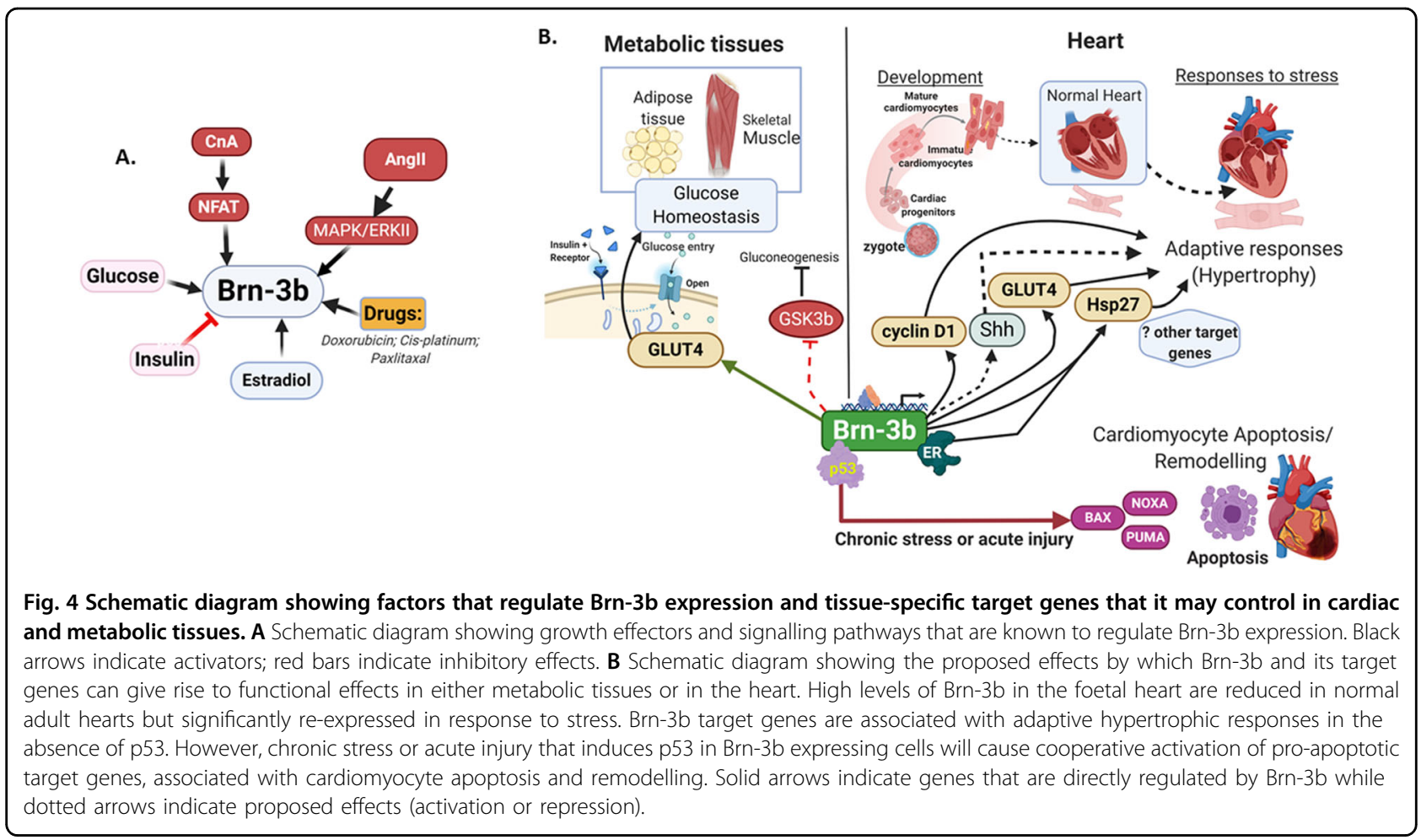

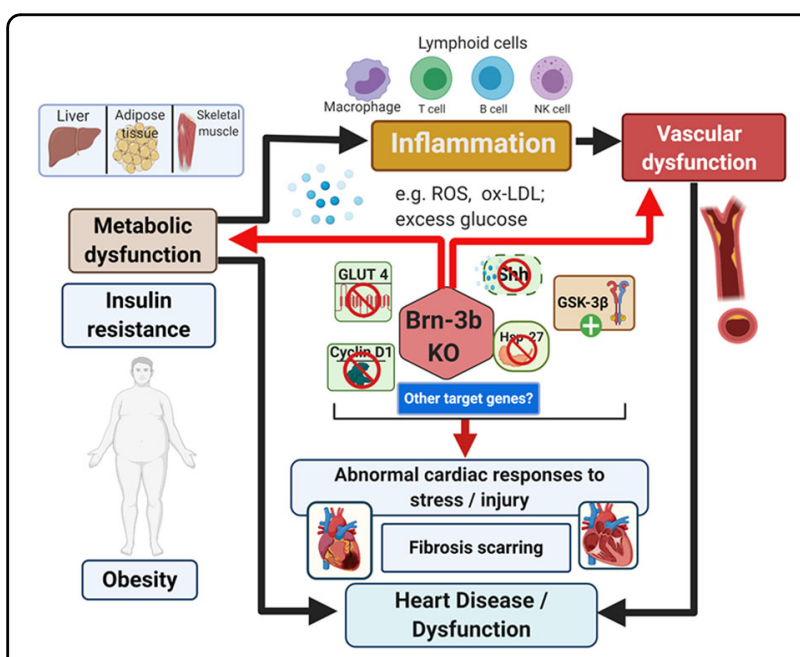

Fig. 5 Schematic diagram to show proposed effects by which loss of Brn-3b and its target genes can cause deregulated function in different tissues. Loss of Brn-3b and its target genes may directly or indirectly contribute to adverse effects in insulin-responsive tissue (skeletal muscle, adipose tissue, liver), vascular smooth muscle cells (VSMC) in blood vessels or cardiomyocytes of the heart. Direct effects could arise if the loss of Brn-3b and its target genes are necessary for controlling normal function in specific tissues. In contrast, indirect effects may result from crosstalk between different systemic effects with metabolic dysfunction, caused by loss of Brn-3b giving rise to pro-inflammatory milieu e.g. reactive oxygen species (ROS), oxidative low-density lipoprotein (Ox-LDL), which, in turn, trigger adverse changes in the heart and vasculature.
CVD is predicted to rise in line with an ongoing obesity epidemic, then understanding the molecular mechanisms by which Brn-3b drives diverse effects in different tissues can provide insights into how the loss of Brn-3b contributes to pathological changes in metabolic and cardiovascular diseases, but could also provide different approaches for earlier diagnosis and effective treatment.

\section{Author contributions}

V.B.-M. provided conceptual design for the review, supervised and assisted with data interpretation, undertook critical appraisal, and revised draft document for intellectual content. Completion and submission of the approved paper. M.S. and E.M.H. were involved in the research and preparation of the figures and drafted the paper and proofreading the revised paper.

\section{Ethics statement}

No ethical approval was required for the preparation of this review.

\section{Funding statement}

V.B.-M. research laboratory is funded by British Heart Foundation (BHF) grants, including $P G / 16 / 73 / 32364, P G / 18 / 55 / 33912$ and $F S / 17 / 8 / 32664$.

\section{Conflict of interest}

The authors declare no competing interests.

\section{Publisher's note}

Springer Nature remains neutral with regard to jurisdictional claims in published maps and institutional affiliations.

Received: 2 November 2020 Revised: 15 February 2021 Accepted: 16 February 2021

Published online: 12 March 2021 


\section{References}

1. Timmis, A. et al. European society of cardiology: cardiovascular disease statistics 2017. Eur. Heart J. 39, 508-579 (2018).

2. Wang, $\mathrm{H}$. et al. Global, regional, and national levels of neonatal, infant, and under-5 mortality during 1990-2013: a systematic analysis for the Global Burden of Disease Study 2013. Lancet 384, 957-979 (2014).

3. Zimmet, P., Alberti, K. G. \& Shaw, J. Global and societal implications of the diabetes epidemic. Nature 414, 782-787 (2001).

4. Yatsuya, $\mathrm{H}$. et al. Global trend in overweight and obesity and its association with cardiovascular disease incidence. Circ. J. 78, 2807-2818 (2014).

5. Lazar, M. A. How obesity causes diabetes: not a tall tale. Science $\mathbf{3 0 7}$, 373-375 (2005).

6. Maharani, A. et al. Cardiovascular disease risk factor prevalence and estimated 10-year cardiovascular risk scores in Indonesia: the SMARThealth Extend study. PLoS ONE 14, e0215219 (2019)

7. Einarson, T. R., Acs, A., Ludwig, C. \& Panton, U. H. Prevalence of cardiovascular disease in type 2 diabetes: a systematic literature review of scientific evidence from across the world in 2007-2017. Cardiovasc. Diabetol. 17, 83 (2018).

8. Selvin, E. et al. Diabetes mellitus, prediabetes, and incidence of subclinical myocardial damage. Circulation 130, 1374-1382 (2014).

9. Group WCRCW. World Health Organization cardiovascular disease risk charts: revised models to estimate risk in 21 global regions. Lancet Glob. Health $\mathbf{7}$ e1332-e1345 (2019).

10. Andersson, J., Wennberg, P., Lundblad, D., Escher, S. A. \& Jansson, J. H. Diabetes mellitus, high BMl and low education level predict sudden cardiac death within $24 \mathrm{~h}$ of incident myocardial infarction. Eur. J. Prev. Cardiol. 23 1814-1820 (2016).

11. Lee, T. I. \& Young, R. A. Transcriptional regulation and its misregulation in disease. Cell 152, 1237-1251 (2013).

12. Vaquerizas, J. M., Kummerfeld, S. K., Teichmann, S. A. \& Luscombe, N. M. A census of human transcription factors: function, expression and evolution. Nat. Rev. Genet. 10, 252-263 (2009).

13. Jardim, T. V. et al. Cardiometabolic disease costs associated with suboptimal diet in the United States: a cost analysis based on a microsimulation model. PLoS Med. 16, e1002981 (2019).

14. Blaschke, F., Takata, Y., Caglayan, E., Law, R. E. \& Hsueh, W. A. Obesity, peroxisome proliferator-activated receptor, and atherosclerosis in type 2 diabetes. Arterioscler Thromb. Vasc. Biol. 26, 28-40 (2006).

15. Weedon, M. N. et al. Combining information from common type 2 diabetes risk polymorphisms improves disease prediction. PLoS Med. 3, e374 (2006).

16. Ferre, $\mathrm{P}$. The biology of peroxisome proliferator-activated receptors: relationship with lipid metabolism and insulin sensitivity. Diabetes 53, S43-S50 (2004).

17. Kadonaga, J. T. Regulation of RNA polymerase II transcription by sequencespecific DNA binding factors. Cell 116, 247-257 (2004).

18. Mele, $\mathrm{L}$. et al. The POU4F2/Brn-3b transcription factor is required for the hypertrophic response to angiotensin II in the heart. Cell Death Dis. 10, 621 (2019).

19. Maskell, L. J. et al. Essential but partially redundant roles for POU4F1/Brn-3a and POU4F2/Brn-3b transcription factors in the developing heart. Cell Death Dis. 8, e2861 (2017).

20. Bitsi, S. et al. Profound hyperglycemia in knockout mutant mice identifies novel function for POU4F2/Brn-3b in regulating metabolic processes. Am. J. Physiol. Endocrinol. Metab. 310, E303-E312 (2016).

21. Farooqui-Kabir, S. R. et al. Cardiac expression of Brn-3a and Brn-3b POU transcription factors and regulation of Hsp27 gene expression. Cell Stress Chaperones 13, 297-312 (2008).

22. Budhram-Mahadeo, V. S. \& Latchman, D. S. Targeting Brn-3b in breast cancer therapy. Expert Opin. Ther. Targets 10, 15-25 (2006).

23. Ripley, B. J., Rahman, M. A., Isenberg, D. A. \& Latchman, D. S. Elevated expression of the Brn-3a and Brn-3b transcription factors in systemic lupus erythematosus correlates with antibodies to Brn-3 and overexpression of Hsp90. Arthritis Rheum. 52, 1171-1179 (2005).

24. Gan, L. et al. POU domain factor Brn-3b is required for the development of a large set of retinal ganglion cells. Proc. Natl Acad. Sci. USA 93, 3920-3925 (1996).

25. Xiang, $M$. et al. Brn-3b: a POU domain gene expressed in a subset of retinal ganglion cells. Neuron 11, 689-701 (1993).

26. Herr, W. et al. The POU domain: a large conserved region in the mammalian pit-1, oct-1, oct-2, and Caenorhabditis elegans unc-86 gene products. Genes Dev. 2, 1513-1516 (1988).
27. Klemm, J. D., Rould, M. A., Aurora, R., Herr, W. \& Pabo, C. O. Crystal structure of the Oct-1 POU domain bound to an octamer site: DNA recognition with tethered DNA-binding modules. Cell 77, 21-32 (1994).

28. Phillips, K. \& Luisi, B. The virtuoso of versatility: POU proteins that flex to fit. $J$ Mol. Biol. 302, 1023-1039 (2000).

29. Lillycrop, K. A et al. A novel POU family transcription factor is closely related to Brn-3 but has a distinct expression pattern in neuronal cells. Nucleic Acids Res. 20, 5093-5096 (1992).

30. Xiang, M. et al. The Brn-3 family of POU-domain factors: primary structure, binding specificity, and expression in subsets of retinal ganglion cells and somatosensory neurons. J. Neurosci. 15, 4762-4785 (1995).

31. Theil, T., Zechner, U., Klett, C., Adolph, S. \& Moroy, T. Chromosomal localization and sequences of the murine Brn-3 family of developmental contro genes. Cytogenet Cell Genet. 66, 267-271 (1994).

32. Gruber, C. A., Rhee, J. M., Gleiberman, A. \& Turner, E. E. POU domain factors of the Brn-3 class recognize functional DNA elements which are distinctive, symmetrical, and highly conserved in evolution. Mol. Cell Biol. 17, 2391-2400 (1997).

33. Ounzain, S. et al. Proliferation-associated POU4F2/Brn-3b transcription factor expression is regulated by oestrogen through ERalpha and growth factors via MAPK pathway. Breast Cancer Res. 13, R5 (2011).

34. Lee, S. A. et al. Expression of the Brn-3b transcription factor correlates with expression of HSP-27 in breast cancer biopsies and is required for maximal activation of the HSP-27 promoter. Cancer Res. 65, 3072-3080 (2005).

35. Xiang, $M$. Requirement for Brn-3b in early differentiation of postmitotic retinal ganglion cell precursors. Dev. Biol. 197, 155-169 (1998).

36. Erkman, L. et al. Role of transcription factors Brn-3.1 and Brn-3.2 in auditory and visual system development. Nature 381, 603-606 (1996).

37. Turner, E. E., Jenne, K. J. \& Rosenfeld, M. G. Brn-3.2: a Brn-3-related transcription factor with distinctive central nervous system expression and regulation by retinoic acid. Neuron 12, 205-218 (1994)

38. Budhram-Mahadeo, V. et al. The closely related POU family transcription factors Brn-3a and Brn-3b are expressed in distinct cell types in the testis. Int J. Biochem. Cell Biol. 33, 1027-1039 (2001).

39. Fujita, R., Ounzain, S., Wang, A. C., Heads, R. J. \& Budhram-Mahadeo, V. S. Hsp27 induction requires POU4F2/Brn-3b TF in doxorubicin-treated breast cancer cells, whereas phosphorylation alters its cellular localisation following drug treatment. Cell Stress Chaperones 16, 427-439 (2011).

40. Budhram-Mahadeo, V. S. et al. Proliferation-associated Brn-3b transcription factor can activate cyclin D1 expression in neuroblastoma and breast cancer cells. Oncogene 27, 145-154 (2008).

41. Samady, L. et al. The Brn-3b POU family transcription factor represses plakoglobin gene expression in human breast cancer cells. Int. J. Cancer $\mathbf{1 1 8}$ 869-878 (2006).

42. Samady, L., Dennis, J., Budhram-Mahadeo, V. \& Latchman, D. S. Activation of CDK4 gene expression in human breast cancer cells by the Brn-3b POU family transcription factor. Cancer Biol. Ther. 3, 317-323 (2004).

43. Dennis, J. H., Budhram-Mahadeo, V. \& Latchman, D. S. The Brn-3b POU family transcription factor regulates the cellular growth, proliferation, and anchorage dependence of MCF7 human breast cancer cells. Oncogene $\mathbf{2 0}$ 4961-4971 (2001).

44. Budhram-Mahadeo, V., Ndisang, D., Ward, T., Weber, B. L. \& Latchman, D. S. The Brn-3b POU family transcription factor represses expression of the BRCA1 anti-oncogene in breast cancer cells. Oncogene 18, 6684-6691 (1999).

45. Nurminen, V., Seuter, S. \& Carlberg, C. Primary vitamin D target genes of human monocytes. Front. Physiol. 10, 194 (2019).

46. Bhargava, A. K., Li, Z. \& Weissman, S. M. Differential expression of four members of the POU family of proteins in activated and phorbol 12myristate 13-acetate-treated Jurkat T cells. Proc. Natl Acad. Sci. USA 90 10260-10264 (1993).

47. Budhram-Mahadeo, V., Fujita, R., Bitsi, S., Sicard, P. \& Heads, R. Co-expression of POU4F2/Brn-3b with p53 may be important for controlling expression of pro-apoptotic genes in cardiomyocytes following ischaemic/hypoxic insults. Cell Death Dis. 5, e1503 (2014).

48. Irshad, S., Pedley, R. B., Anderson, J., Latchman, D. S. \& Budhram-Mahadeo, V. The Brn-3b transcription factor regulates the growth, behavior, and invasiveness of human neuroblastoma cells in vitro and in vivo. J. Biol. Chem. 279, 21617-21627 (2004).

49. Gan, L., Wang, S. W., Huang, Z. \& Klein, W. H. POU domain factor Brn-3b is essential for retinal ganglion cell differentiation and survival but not for initia cell fate specification. Dev. Biol. 210, 469-480 (1999). 
50. Pan, L., Deng, M., Xie, X. \& Gan, L. ISL1 and BRN3B co-regulate the differentiation of murine retinal ganglion cells. Development 135, 1981-1990 (2008)

51. Milton, N. G., Bessis, A., Changeux, J. P. \& Latchman, D. S. The neuronal nicotinic acetylcholine receptor alpha 2 subunit gene promoter is activated by the Brn-3b POU family transcription factor and not by Brn-3a or Brn-3c. J. Biol. Chem. 270, 15143-15147 (1995).

52. Budhram-Mahadeo, V. et al. Activation of the alpha-internexin promoter by the Brn-3a transcription factor is dependent on the N-terminal region of the protein. J. Biol. Chem. 270, 2853-2858 (1995)

53. Smith, M. D., Dawson, S. J. \& Latchman, D. S. Inhibition of neuronal process outgrowth and neuronal specific gene activation by the Brn-3b transcription factor. J. Biol. Chem. 272, 1382-1388 (1997).

54. $\mathrm{Mu}, \mathrm{X}$. et al. Discrete gene sets depend on POU domain transcription factor Brn3b/Brn-3.2/POU4f2 for their expression in the mouse embryonic retina. Development 131, 1197-1210 (2004).

55. Plaza, S., Hennemann, H., Moroy, T., Saule, S. \& Dozier, C. Evidence that POU factor Brn-3B regulates expression of Pax-6 in neuroretina cells. J. Neurobiol. 41, 349-358 (1999).

56. Qiu, F., Jiang, H. \& Xiang, M. A comprehensive negative regulatory program controlled by Brn3b to ensure ganglion cell specification from multipotential retinal precursors. J. Neurosci. 28, 3392-3403 (2008).

57. Maskell, L. J., Mahadeo, A. V. \& Budhram-Mahadeo, V. S. POU4F2/Brn-3b transcription factor is associated with survival and drug resistance in human ovarian cancer cells. Oncotarget 9, 36770-36779 (2018).

58. Mu, X., Fu, X., Beremand, P. D., Thomas, T. L. \& Klein, W. H. Gene regulation logic in retinal ganglion cell development: Isl1 defines a critical branch distinct from but overlapping with Pou4f2. Proc. Natl Acad. Sci. USA 105, 6942-6947 (2008).

59. Zhang, $Q$. et al. Regulation of $B r n 3 b$ by $D L X 1$ and $D L X 2$ is required for retinal ganglion cell differentiation in the vertebrate retina. Development $\mathbf{1 4 4}$ 1698-1711 (2017).

60. Budhram-Mahadeo, V., Parker, M. \& Latchman, D. S. POU transcription factors Brn-3a and Brn-3b interact with the estrogen receptor and differentially regulate transcriptional activity via an estrogen response element. Mol. Cell Biol. 18, 1029-1041 (1998).

61. Budhram-Mahadeo, V. S. et al. Brn-3b enhances the pro-apoptotic effects of p53 but not its induction of cell cycle arrest by cooperating in transactivation of bax expression. Nucleic Acids Res. 34, 6640-6652 (2006).

62. Klinge, C. M. Estrogen receptor interaction with estrogen response elements. Nucleic Acids Res. 29, 2905-2919 (2001).

63. Farooqui-Kabir, S. R. et al. Regulation of Hsp27 expression and cell survival by the POU transcription factor Brn3a. Cell Death Differ. 11, 1242-1244 (2004).

64. Zhang, H. L., Jia, K. Y., Sun, D. \& Yang, M. Protective effect of HSP27 in atherosclerosis and coronary heart disease by inhibiting reactive oxygen species. J. Cell Biochem. 120, 2859-2868 (2019).

65. Song, T. F. et al. Small interfering RNA-mediated silencing of heat shock protein 27 (HSP27) Increases chemosensitivity to paclitaxel by increasing production of reactive oxygen species in human ovarian cancer cells HO8910. J. Int. Med. Res. 37, 1375-1388 (2009).

66. Zhang, B. et al. Heat shock protein 27 phosphorylation regulates tumor cell migration under shear stress. Biomolecules 9, 50 (2019).

67. Lee, J. W. et al. HSP27 regulates cell adhesion and invasion via modulation of focal adhesion kinase and MMP-2 expression. Eur. J. Cell Biol. 87, 377-387 (2008).

68. Pichon, S., Bryckaert, M. \& Berrou, E. Control of actin dynamics by p38 MAP kinase - Hsp27 distribution in the lamellipodium of smooth muscle cells. J. Cell Sci. 117, 2569-2577 (2004).

69. Piotrowicz, R. S., Hickey, E. \& Levin, E. G. Heat shock protein 27 kDa expression and phosphorylation regulates endothelial cell migration. FASEB J. 12, 1481-1490 (1998).

70. Ghayour-Mobarhan, M., Rahsepar, A. A., Tavallaie, S., Rahsepar, S. \& Ferns, G. A. The potential role of heat shock proteins in cardiovascular disease: evidence from in vitro and in vivo studies. Adv. Clin. Chem. 48, 27-72 (2009).

71. Mercer, E. J., Lin, Y. F., Cohen-Gould, L. \& Evans, T. Hspb7 is a cardioprotective chaperone facilitating sarcomeric proteostasis. Dev. Biol. 435, 41-55 (2018).

72. Wu, T. et al. HSPB7 is indispensable for heart development by modulating actin filament assembly. Proc. Natl Acad. Sci. USA 114, 11956-11961 (2017).

73. Venkatakrishnan, C. D. et al. HSP27 regulates p53 transcriptional activity in doxorubicin-treated fibroblasts and cardiac H9c2 cells: p21 upregulation and
G2/M phase cell cycle arrest. Am. J. Physiol. Heart Circ. Physiol. 294 H1736-H1744 (2008)

74. Barros, R. P. \& Gustafsson, J. A. Estrogen receptors and the metabolic network. Cell Metab. 14, 289-299 (2011).

75. Schuster, I. et al. Cardiomyocyte-specific overexpression of oestrogen receptor beta improves survival and cardiac function after myocardial infarction in female and male mice. Clin. Sci. 130, 365-376 (2016).

76. Wang, Y. C. et al. Oestrogen inhibits BMP4-induced BMP4 expression in cardiomyocytes: a potential mechanism of oestrogen-mediated protection against cardiac hypertrophy. Br. J. Pharm. 172, 5586-5595 (2015).

77. Grohe, C., Kahlert, S., Lobbert, K. \& Vetter, H. Expression of oestrogen receptor alpha and beta in rat heart: role of local oestrogen synthesis. J. Endocrinol. 156, R1-R7 (1998).

78. Kararigas, G., Nguyen, B. T. \& Jarry, H. Estrogen modulates cardiac growth through an estrogen receptor alpha-dependent mechanism in healthy ovariectomized mice. Mol. Cell Endocrinol. 382, 909-914 (2014).

79. Meyer, M. R., Haas, E. \& Barton, M. Gender differences of cardiovascular disease: new perspectives for estrogen receptor signaling. Hypertension 47, 1019-1026 (2006).

80. Samady, L. et al. The Brn-3b POU family transcription factor represses plakoglobin gene expression in human breast cancer cells. Int. J. Cancer $\mathbf{1 1 8}$ 869-878 (2006).

81. Schmitt, C. A. et al. Dissecting p53 tumor suppressor functions in vivo. Cancer Cell 1, 289-298 (2002).

82. Taylor, W. R. \& Stark, G. R. Regulation of the G2/M transition by p533. Oncogene 20, 1803-1815 (2001).

83. Tang, H. Y. et al. Constitutive expression of the cyclin-dependent kinase inhibitor p21 is transcriptionally regulated by the tumor suppressor protein p53. J. Biol. Chem. 273, 29156-29163 (1998).

84. Aylon, Y. \& Oren, M. Living with p53, dying of p53. Cell 130, 597-600 (2007).

85. Oren, M. Decision making by p53: life, death and cancer. Cell Death Differ. 10, 431-442 (2003).

86. Mansilla, S., Priebe, W. \& Portugal, J. Transcriptional changes facilitate mitotic catastrophe in tumour cells that contain functional p53. Eur. J. Pharm. $\mathbf{5 4 0}$ 34-45 (2006).

87. Deems, R. O. et al. Expression of human GLUT4 in mice results in increased insulin action. Diabetologia 37, 1097-1104 (1994).

88. Stenbit, A. E. et al. GLUT4 heterozygous knockout mice develop muscle insulin resistance and diabetes. Nat. Med. 3, 1096-1101 (1997).

89. Eldar-Finkelman, H. \& Krebs, E. G. Phosphorylation of insulin receptor substrate 1 by glycogen synthase kinase 3 impairs insulin action. Proc. Natl Acad. Sci. USA 94, 9660-9664 (1997).

90. Nikoulina, S. E. et al. Inhibition of glycogen synthase kinase 3 improves insulin action and glucose metabolism in human skeletal muscle. Diabetes $\mathbf{5 1}$, 2190-2198 (2002).

91. Henry, R. R., Abrams, L., Nikoulina, S. \& Ciaraldi, T. P. Insulin action and glucose metabolism in nondiabetic control and NIDDM subjects. Comparison using human skeletal muscle cell cultures. Diabetes 44, 936-946 (1995).

92. Bhalla, K. et al. Cyclin D1 represses gluconeogenesis via inhibition of the transcriptional coactivator PGC1alpha. Diabetes 63, 3266-3278 (2014).

93. Clark, K. L., Yutzey, K. E. \& Benson, D. W. Transcription factors and congenital heart defects. Annu. Rev. Physiol. 68, 97-121 (2006).

94. Gittenberger-de Groot, A. C., Bartelings, M. M., DeRuiter, M. C. \& Poelmann, R. E. Basics of cardiac development for the understanding of congenital heart malformations. Pediatr. Res. 57, 169-176 (2005).

95. Habets, P. E., Moorman, A. F. \& Christoffels, V. M. Regulatory modules in the developing heart. Cardiovasc Res. 58, 246-263 (2003).

96. Moorman, A. F. \& Christoffels, V. M. Cardiac chamber formation: development, genes, and evolution. Physiol. Rev. 83, 1223-1267 (2003).

97. Ahuja, P., Sdek, P. \& MacLellan, W. R. Cardiac myocyte cell cycle control in development, disease, and regeneration. Physiol. Rev. 87, 521-544 (2007).

98. Hudson, C. D., Morris, P. J., Latchman, D. S. \& Budhram-Mahadeo, V. S. Brn-3a transcription factor blocks p53-mediated activation of proapoptotic target genes Noxa and Bax in vitro and in vivo to determine cell fate. J. Biol. Chem. 280, 11851-11858 (2005).

99. Budhram-Mahadeo, V., Morris, P. J. \& Latchman, D. S. The Brn-3a transcription factor inhibits the pro-apoptotic effect of p53 and enhances cell cycle arrest by differentially regulating the activity of the p53 target genes encoding Bax and p21(CIP1Maf1). Oncogene 21, 6123-6131 (2002).

100. Ensor, E., Mathews, K., Payne, S. M. D. \& Latchman, D. S. Sensory neurons from mice lacking the Brn-3b POU family transcription factor are resistant to 
death-inducing stimuli both in vitro and in vivo. Brain Res Mol. Brain Res. 117, 206-212 (2003).

101. Bartman, T. \& Hove, J. Mechanics and function in heart morphogenesis. Dev. Dyn. 233, 373-381 (2005)

102. McEvilly, R. J. et al. Requirement for Brn-3.0 in differentiation and survival of sensory and motor neurons. Nature 384, 574-577 (1996).

103. Xiang, M., Gan, L., Zhou, L., Klein, W. H. \& Nathans, J. Targeted deletion of the mouse POU domain gene Brn-3a causes selective loss of neurons in the brainstem and trigeminal ganglion, uncoordinated limb movement, and impaired suckling. Proc. Natl Acad. Sci. USA 93, 11950-11955 (1996).

104. Liao, W. C., Juo, L. Y., Shih, Y. L., Chen, Y. H. \& Yan, Y. T. HSPB7 prevents cardiac conduction system defect through maintaining intercalated disc integrity. PLoS Genet. 13, e1006984 (2017)

105. Tanonaka, K., Yoshida, H., Toga, W., Furuhama, K. \& Takeo, S. Myocardial heat shock proteins during the development of heart failure. Biochem. Biophys. Res. Commun. 283, 520-525 (2001).

106. Sutton, M. G. \& Sharpe, N. Left ventricular remodeling after myocardial infarction: pathophysiology and therapy. Circulation 101, 2981-2988 (2000).

107. Heineke, J. \& Molkentin, J. D. Regulation of cardiac hypertrophy by intracellular signalling pathways. Nat. Rev. Mol. Cell Biol. 7, 589-600 (2006).

108. Frey, N. \& Olson, E. N. Cardiac hypertrophy: the good, the bad, and the ugly Annu. Rev. Physiol. 65, 45-79 (2003).

109. Richey, P. A. \& Brown, S. P. Pathological versus physiological left ventricular hypertrophy: a review. J. Sports Sci. 16, 129-141 (1998).

110. Selvetella, G., Hirsch, E., Notte, A., Tarone, G. \& Lembo, G. Adaptive and maladaptive hypertrophic pathways: points of convergence and divergence. Cardiovasc Res. 63, 373-380 (2004).

111. Mann, D. L. \& Bristow, M. R. Mechanisms and models in heart failure: the biomechanical model and beyond. Circulation 111, 2837-2849 (2005).

112. Lips, D. J., deWindt, L. J., van Kraaij, D. J. \& Doevendans, P. A. Molecular determinants of myocardial hypertrophy and failure: alternative pathways for beneficial and maladaptive hypertrophy. Eur. Heart J. 24, 883-896 (2003).

113. Sergeeva, I. A. \& Christoffels, V. M. Regulation of expression of atrial and brain natriuretic peptide, biomarkers for heart development and disease. Biochim Biophys. Acta 1832, 2403-2413 (2013).

114. Gardner, D. G. Natriuretic peptides: markers or modulators of cardiac hypertrophy? Trends Endocrinol. Metab. 14, 411-416 (2003).

115. Busk, P. K. \& Hinrichsen, R. Cyclin D in left ventricle hypertrophy. Cell Cycle $\mathbf{2}$ 91-95 (2003).

116. Tamamori-Adachi, M. et al. Expression of cyclin D1 and CDK4 causes hypertrophic growth of cardiomyocytes in culture: a possible implication for cardiac hypertrophy. Biochem Biophys. Res Commun. 296 274-280 (2002)

117. Pandya, K., Porter, K., Rockman, H. A. \& Smithies, O. Decreased betaadrenergic responsiveness following hypertrophy occurs only in cardiomyocytes that also re-express beta-myosin heavy chain. Eur. J. Heart Fail 11, 648-652 (2009).

118. Yokota, N. et al. Dissociation of cardiac hypertrophy, myosin heavy chain isoform expression, and natriuretic peptide production in DOCA-salt rats. Am. J. Hypertens. 8, 301-310 (1995).
119. Stuck, B. J., Lenski, M., Bohm, M. \& Laufs, U. Metabolic switch and hypertrophy of cardiomyocytes following treatment with angiotensin II are prevented by AMP-activated protein kinase. J. Biol. Chem. 283, 32562-32569 (2008).

120. Stenbit, A. E. et al. Preservation of glucose metabolism in hypertrophic GLUT4-null hearts. Am. J. Physiol. Heart Circ. Physiol. 279, H313-H318 (2000)

121. Katz, E. B., Stenbit, A. E., Hatton, K., DePinho, R. \& Charron, M. J. Cardiac and adipose tissue abnormalities but not diabetes in mice deficient in GLUT4. Nature 377, 151-155 (1995).

122. Kopelman, P. G. Obesity as a medical problem. Nature 404, 635-643 (2000)

123. Koyanagi, $\mathrm{A}$. et al. The association between obesity and severe disability among adults aged 50 or over in nine high-income, middle-income and low-income countries: a cross-sectional study. BMJ Open 5, e007313 (2015).

124. Balakumar, P., Maung, U. K. \& Jagadeesh, G. Prevalence and prevention of cardiovascular disease and diabetes mellitus. Pharm. Res 113, 600-609 (2016).

125. McAloon, C. J. et al. The changing face of cardiovascular disease 2000-2012 an analysis of the world health organisation global health estimates data. Int. J. Cardiol. 224, 256-264 (2016).

126. Wende, A. R. et al. Glucose transporter 4-deficient hearts develop maladaptive hypertrophy in response to physiological or pathological stresses. Am. J. Physiol. Heart Circ. Physiol. 313, H1098-H1108 (2017).

127. Nikoulina, S. E. et al. Potential role of glycogen synthase kinase-3 in skeletal muscle insulin resistance of type 2 diabetes. Diabetes 49, 263-271 (2000).

128. Antos, C. L. et al. Activated glycogen synthase-3 beta suppresses cardiac hypertrophy in vivo. Proc. Natl Acad. Sci. USA 99, 907-912 (2002).

129. Hardt, S. E. \& Sadoshima, J. Glycogen synthase kinase-3beta: a novel regulator of cardiac hypertrophy and development. Circ. Res. 90, 1055-1063 (2002).

130. Woulfe, K. C. et al. Glycogen synthase kinase-3beta regulates post-myocardial infarction remodeling and stress-induced cardiomyocyte proliferation in vivo. Circ. Res. 106, 1635-1645 (2010).

131. Wang, Y., Dakubo, G. D., Thurig, S., Mazerolle, C. J. \& Wallace, V. A. Retinal ganglion cell-derived sonic hedgehog locally controls proliferation and the timing of RGC development in the embryonic mouse retina. Development 132, 5103-5113 (2005)

132. Dyer, L. A. \& Kirby, M. L. Sonic hedgehog maintains proliferation in secondary heart field progenitors and is required for normal arterial pole formation. Dev. Biol. 330, 305-317 (2009).

133. Paulis, L. et al. Activation of sonic hedgehog signaling in ventricular cardiomyocytes exerts cardioprotection against ischemia reperfusion injuries. Sci. Rep. 5, 7983 (2015).

134. Lavine, K. J., Kovacs, A. \& Ornitz, D. M. Hedgehog signaling is critical for maintenance of the adult coronary vasculature in mice. J. Clin. Investig. 118 2404-2414 (2008)

135. Xiao, Q. et al. Increased expression of sonic hedgehog restores diabetic endothelial progenitor cells and improves cardiac repair after acute myocardial infarction in diabetic mice. Int. J. Mol. Med. 44, 1091-1105 (2019).

136. Gerdts, E. \& Regitz-Zagrosek, V. Sex differences in cardiometabolic disorders Nat. Med. 25, 1657-1666 (2019).

137. Bots, S. H., Peters, S. A. E. \& Woodward, M. Sex differences in coronary heart disease and stroke mortality: a global assessment of the effect of ageing between 1980 and 2010. BMJ Glob. Health 2, e000298 (2017). 